Bulletin d'Histoire Contemporaine de l'Espagne

$50 \mid 2016$

Les intellectuels en Espagne, de la dictature à la démocratie (1939-1986)

\title{
Las Españas de Rafael Calvo Serer y Pedro Laín Entralgo
}

Les Espagne de Rafael Calvo Serer et de Pedro Lain Entralgo

Spain of Rafael Calvo Serer and Pedro Lain Entralgo

\section{Antoni Raja}

\section{OpenEdition}

\section{Journals}

Edición electrónica

URL: http://journals.openedition.org/bhce/553

DOI: $10.4000 /$ bhce.553

ISSN: 1968-3723

Editor

Presses Universitaires de Provence

Edición impresa

Fecha de publicación: 1 diciembre 2016

Paginación: 99-110

ISSN: 0987-4135

Referencia electrónica

Antoni Raja, "Las Españas de Rafael Calvo Serer y Pedro Laín Entralgo », Bulletin d'Histoire

Contemporaine de l'Espagne [En línea], 50 | 2016, Publicado el 09 octubre 2018, consultado el 19

septiembre 2020. URL : http://journals.openedition.org/bhce/553 ; DOI : https://doi.org/10.4000/bhce 553 


\title{
Las Españas de Rafael Calvo Serer y Pedro Laín Entralgo
}

\author{
Antoni RAJA
}

Universidad Pompeu i Fabra

$\mathrm{E}$

n 1939, la España republicana y lo que ella representaba fue finalmente derrotada en el campo de batalla en manos del «Ejército Nacional». Después del descalabro militar republicano, el régimen victorioso del general Francisco Franco Bahamonde (1936-1975) hizo poco o nada por reconciliar esas dos Españas que se habían matado mutuamente desde 1936. Utilizando la censura, la purga, el exilio y el asesinato, la «nueva España» llegó para mantener la postración de un amplio sector de la sociedad española. El exilio se llevó a muchísimos españoles y entre ellos a no pocos académicos y pensadores que habían participado de la querella sobre el ser de España.

Con ese estado de cosas, los intelectuales franquistas tuvieron la ardua labor de reconstruir el pasado español en concordancia con los nuevos principios de la «España de la Victoria». Los españoles derrotados y sus ideas no fueron considerados como parte de España sino como anti-españoles que no habían hecho más que traicionar los valores eternos que España representaba para favorecer la extranjerización y la desnaturalización de lo que verdaderamente era España' ${ }^{2}$. Con esta nueva perspectiva en mente, los intelectuales orgánicos del nuevo régimen no hacían más que acabar con el sempiterno problema español. De hecho, para aquellos la cuestión no había existido jamás ya que de lo que realmente se trataba era de una lucha contra aquellos que habían destruido España desde dentro, contra aquellos que habían abrazado principios poco españoles como el socialismo, el liberalismo o la democracia. La España republicana encarnaba todos aquellos problemas que debían ser eliminados si se quería recuperar la grandeza nacional.

Si nos ceñimos estrictamente a una perspectiva histórica, el problema de España no fue más que una sucesión de soluciones a las supuestas complicaciones que el país sufría. Algunos autores ven en el gran literato castellano, Francisco de Quevedo y Villegas (15801645), como uno de los primeros hombres que percibieron aquella dificultad hispana para mantenerse entre los más importantes países del mundo ${ }^{2}$. De hecho, Quevedo empezaba a comprender que los países europeos del momento empezaban a plantar cara y a poner en jaque al Imperio castellano. Pero fue en el siglo XIX cuando el problema fue percibido con toda su crudeza por unas generaciones de intelectuales que se enfrentaron a las sucesivas

1 Sobre los debates en el seno de los primeros años de la España nacional: José ANDRÉs-GALLEGo, ¿Fascismo o Estado católico? Ideología, religión y censura en la España de Franco, 1937-1941, Madrid, Ediciones Encuentro, 1997.

2 Berhardt Scнмid, El problema español de Quevedo a Manuel Azaña, Madrid, EDICUSA, 1976. 
invasiones francesas, las guerras civiles decimonónicas y la derrota final ante los Estados Unidos de Norteamérica en $1898^{3}$.

Todos los participantes en ese debate metafísico sobre los males de España aportaban una nueva perspectiva y una nueva solución a ese malestar, pero no parecía que ninguna de esas nuevas interpretaciones pudiera ser la auténtica salida a los males nacionales. Por eso es posible ver en la Guerra Civil Española (1936-1939) un intento militar de dos interpretaciones de España para conseguir imponer un modelo político, social y económico definitivo que superara esa tensión centenaria. Y exactamente eso es lo que se intentó desde los nuevos resortes de poder bajo la atenta mirada del dictador Francisco Franco: eliminar cualquier referencia positiva al pasado liberal y socialista español para demostrar que los únicos responsables de la guerra fueron los equivocadísimos anti-españoles.

Así pues, todo parecía apuntar a una definitiva y total victoria de una visión de España, pero con el tiempo se vería que no era así. Incluso bajo la férrea mirada de la censura algunos españoles consideraban que había una «revolución pendiente» que el franquismo como régimen estaba obviando, y que la consecuencia directa de aquella actuación sería la perpetuación del problema español.

Uno de estos autores fue el falangista aragonés, Pedro Laín Entralgo (1908-2001), quien, en 1949, publicó un corto escrito llamado España como problema', que provocó una airada reacción de no pocos sectores de la sociedad española de la victoria. Ya desde los inicios de la Guerra Civil Española Laín había expuesto sus ideas en distintas publicaciones para intelectuales o periódicos de difusión popular, llegando a un clímax ideológico con la aparición impresa de «[...] una conferencia de su autor en el Primer Congreso Nacional de los Sindicatos de la Falange [...]», conocida como Los valores morales del nacionalsindicalismo ${ }^{5}$. En la mayoría de sus escritos políticos el falangista se había mostrado partidario de una nueva España fascista al estilo de lo que el dictador italiano Benito Mussolini (1883-1945) venía construyendo desde 1922, cosa que no todos los elementos de la coalición franquista compartían. La Iglesia, el Ejército y todos aquellos que veían el poder de Falange Española como amenaza al statu quo movilizaron sus fuerzas contra ese partido que parecía querer destruir parte de aquellos que habían luchado contra la Segunda República Española (1931-1939). De este modo, Laín se situaba en la órbita del discurso de la «revolución pendiente».

Desde un punto de vista intelectual, a esa interpretación fascista de España se opuso la respuesta pública hecha por el católico y monárquico valenciano, Rafael Calvo Serer (1916-1988), quien publicó su España, sin problema, en el mismo $1949^{6}$. Este libro no era en sí mismo un escrito único sino una compilación de artículos de Calvo aparecidos durante la segunda mitad de la década de los cuarenta. En este laureado trabajo, el monárquico exponía que España necesitaba algo muy diverso de lo que había escrito Laín, puesto que él provenía de una cultura política diferente a la que pertenecía el falangista. Para él la monarquía tradicional hispana se alzaba como la única solución al problema de España. La vuelta a los orígenes permitiría a los españoles reconquistar lo perdido, no había lugar para una nueva revolución de signo falangista.

3 Sobre el pensamiento español en el siglo XIX: José Álvarez Junco, Mater dolorosa. La idea de España en el siglo XIX, Madrid, Taurus, 2001.

4 Pedro Lain Entralgo, España como problema, Madrid, Seminario de Problemas Hispano-americanos, 1949.

5 Pedro Lain Entralgo, Los valores morales del nacionalsindicalismo, Madrid, Editora Nacional, 1941.

6 Rafael Calvo Serer, España, sin problema, Madrid, Biblioteca del Pensamiento Actual, 1949. 
El debate que tuvo lugar entre las distintas familias franquistas entorno a la idea de España ha sido estudiado en bastantes ocasiones, aunque la cuestión de España se suele comprender como la plasmación de dos visiones sobre el pasado patrio, esto es, la España progresista que mira al futuro y la España conservadora que anhela al retorno al pasado ${ }^{7}$. El mismo Laín lo dejó por escrito cuando afirmó que ese problema no era más que:

[...] la dramática inhabilidad de los españoles, desde hace siglo y medio [¿1808?], para hacer de su patria un país mínimamente satisfecho de su constitución política y social, y acerca de las más importantes reacciones intelectuales frente a esa interna vicisitud de nuestra historia ${ }^{8}$

Si aceptamos como verdadero el texto de Laín nos topamos necesariamente con un problema al que sólo Calvo parece capaz de poder responder. La cuestión es que si el problema de España era la plasmación intelectual de dos cosmovisiones sobre el país derivadas de dos posiciones frente la modernidad, ya fuera su aceptación o su negación, ¿cómo podía ser que una vez derrotada una de ellas en 1939 volviera a aparecer bajo la sombra de la victoria? Ante esta pregunta Calvo Serer se mostraba mucho más coherente pidiendo a todos los miembros de la «España de la victoria» que mantuvieran la unidad política conseguida contra la Segunda República. A su entender no había espacio en la «nueva España» para las dudas y los seguidismos de aquellos que habían llevado al país al caos.

Es por este motivo que consideramos el problema de España como algo más que una disputa entre dos visiones de España. Según parece, tendríamos como mínimo dos perspectivas posibles dentro del bloque franquista y otras tantas o más en el exilio republicano ${ }^{9}$. De este modo, es fundamental comprender las Españas posibles dentro de la dictadura franquista para establecer las similitudes y diferencias entre las distintas familias de la coalición nacional. Y pensamos que es en el debate sobre España donde podemos encontrar las propuestas que se ofrecían a los dilemas planteados por el mundo moderno.

Por lo tanto, si aceptamos qu'en la España de Franco había más de una posible solución a los problemas con los que se topaba la dictadura comprenderemos que la coalición franquista no fue un bloque monolítico sino una contraposición de fuerzas que coexistían más por oposición al sistema liberal republicano que por la existencia d'un proyecto común. A modo de ejemplo, los hechos de la Basílica de Nuestra Señora de Begoña, en 1942, no serían más que una manifestación física de aquellas tensiones políticas e intelectuales; pero fue en el mundo de las letras donde más claramente se comprendieron las diferentes propuestas políticas de la «nueva España» ya que Franco era mucho más permisivo en este ámbito que en la lucha política abierta ${ }^{10}$.

7 Dos de los mejores y más recientes estudios sobre la cuestión: Santos JulıA, Historia de las dos Españas, Madrid, Taurus, 2004; Ismael Saz Campos, España contra España, Madrid, Marcial Pons, 2003.

8 Pedro Lain Entralgo, España como.... p.13.

9 Para mencionar sólo algunos: Julio Almeıda, El problema de España en Américo Castro, Córdoba, Servicio de Publicaciones de la Universidad de Córdoba, 1993; Alfonso Botri, Cielo y dinero. El nacionalcatolicismo en España, (1881-1975), Madrid, Alianza, 1992; Carolyn P. Boyd, Historia Patria. Política, historia e identidad nacional en España: 1875-1975, Barcelona, Ediciones Pomares-Corredor, 2000; Gonzalo CAPELlán dE Miguel, La España armónica. El proyecto del krausismo español para una sociedad en conflicto, Madrid, Biblioteca Nueva, 2006; Elias diAz, Pensamiento español, 1939-1973, Madrid, EDICUSA, 1974; Álvaro FERRARY, El Franquismo: minorías políticas y conflictos ideológicos 1936-1956, Pamplona, EUNSA, 1993; Dolores Franco, España como preocupación, Barcelona, Argos Vergara, 1980; Ricardo GARCía CARCEL, La construcción de las Historias de España, Madrid, Marcial Pons, 2004; Jordi Gracia, La resistencia silenciosa. Fascismo y cultura en España, Barcelona, Anagrama, 2004

10 Alfonso Lazo, Una familia mal avenida. Falange, Iglesia y Ejército, Madrid, Sintesis, 2008. 
Como se ha mencionado más arriba, Pedro Laín escribió en 1949 España como problema poniendo sobre la mesa la cuestión sempiterna de la problematicidad del hecho español. Según los participantes en este debate había algo que hacía de España un país problemático e incapaz de adaptarse a los tiempos modernos tal y como hacía otros países europeos ${ }^{11}$. Y es esta la piedra de toque para comprender el debate a lo largo del tiempo: la modernidad y la modernización.

Cuando la tradición pesaba como una única losa no había más opción que mantenerse en la vía de lo heredado, pero cuando emergió un mundo moderno de posibilidades fundamentado en el cambio y la voluntad todo fue oportunidad ${ }^{12}$. Con la emergencia de lo nuevo, lo antiguo se convirtió en sólo una de las dos posibles salidas a cualquier cuestión que se planteara. La Europa cristiana y medieval era una opción real para muchos europeos como lo fue la Europa de los Estados-Nación y moderna que empezaba a despuntar desde el siglo XVI ${ }^{13}$. Desde entonces y de manera creciente, los europeos empezaron a comprender que no había limitaciones metafisicas a sus decisiones personales como no había un destino fijado en las Escrituras. La voluntad empezaba su camino. Ese cambio epistémico y ontológico hizo de los europeos animales abiertos al cambio, pero asaltados constantemente por las dudas y los reparos frente a la constante multiplicación de posibilidades e interpretaciones.

Además de la modernidad como vehículo ideológico y de comportamiento apareció un nuevo mundo material que ofrecía nuevas soluciones a problemas antiguos: la modernización. Las sociedades cambiaban por el impacto de la tecnología y de nuevas ideas que permitían a los humanos cambiar hábitos y tradiciones. Las antiguas creencias y prácticas sociales quedaban paso a paso sepultadas por «nuevas» tradiciones que se imponían con más o menos facilidad. Algunos se sumaron al cambio mientras que otros abominaron su presencia por la sensación de finitud a la que condenaban al pasado y al presente.

El mundo moderno, pues, todo era posible, pero también duda, perspectivismo y falta de sentido. No todos los occidentales estaban dispuestos a aceptar los elementos desnaturalizadores que contenía la modernización de las costumbres. Algunos empezaron a pensar que ese nuevo mundo en el que el hombre y el placer eran el centro de la experiencia debía ser rechazado para abrazar la tradición y la fe.

Frente a esas dos ideas los autores españoles tuvieron que elegir qué preferían: modernidad o tradición. Esta cuestión dividió profundamente a las dos Españas, ya que mientras que una prefería avanzar hacia el futuro dentro del marco occidental, otra optaba claramente por el inmovilismo y la creencia que todo lo que hacían los modernos se hacía contra el Rey, la tradición y contra Dios. Algunos afirmarían que las dos opciones estaban claramente delimitadas gracias a la tensión entre las izquierdas y las derechas, pero como se verá esto es algo mucho más complejo. En los pensadores considerados progresistas había socialistas utópicos que anhelaban una vuelta a un mundo mejor, tradición iniciada en tiempos contemporáneos por el filósofo suizo, Jean Jacques Rousseau (1712-1778); otros pensadores pertenecientes a la misma cultura política pensaban que el pasado era el

11 Sobre los problemas de los pensadores españoles y lo moderno: Antonio ELORZA y Carmen LOPEZ Alonso, Arcaísmo y modernidad. Pensamiento político en España, siglos XIX-XX, Madrid, historia 16, 1989.

12 Stephen Toulmin, Cosmópolis. El trasfondo de la modernidad, Barcelona, Península, 2001.

13 Entre otros muchos volúmenes sobre la cuestión: Jonathan I. IsraEL, Enlightenment contested. Philosophy, Modernity, and the Emancipation of Man 1670-1752, Oxford, Oxford University Press, 2006; Paolo Rossi, The Birth of Modern Science, New York, Blackwell, 2001. 
problema y que solamente con la destrucción del mismo se podía llegar a una posición de felicidad prometida por los philosophes de la Ilustración. Así pues, unos lloraban por un paraíso perdido mientras que otros soñaban con la construcción de uno ${ }^{14}$.

La cuestión, empero, fue que las «derechas» como colectivo también se dividieron en el siglo XIX entre aquellas que prometían una restauración de un mundo perdido por los excesos de la revolución y la voluntad individual, y aquellos que pensaban que el futuro era un mundo mejor siempre y cuando se rechazaran frontalmente los principios rectores de la sociedad liberal democrática, no para volver al pasado sino para superarla y mejorarla mediante las ideas del nuevo nacionalismo radical. Mientras que los contrarrevolucionarios veían en la época medieval idealizada un periodo de armonía y bondad, los nuevos corrientes derechistas consideraban que el mundo estaba sometido ineludiblemente a una lucha de opuestos que sólo sería superada por la síntesis final hecha dentro de la nación.

Es debido a la existencia de esas distintas derechas que el franquismo siempre se ha visto como una coalición y no como un grupo homogéneo ${ }^{15}$. Es por ese motivo que no nos debería sorprender que un autor de la «España nacional» siguiera pensando que había un problema a solucionar, en 1949. Con esa posición abría la puerta a una revisión de la España del exilio en la que algunos, y este concepto es importante, podrían ser asimilados en la nueva España. Para algunos autores posteriores, la visión asimilacionista de Laín era muy distinta de la integrista de Calvo, afirmando implícitamente que el falangista era un demócrata encubierto en tiempos difíciles. A nuestro entender esa visión sobre el sector representado por Laín ${ }^{16}$ se basa en una interpretación a posteriori fundamentada en los años en los que el falangista no tuvo otra opción que pasar a una oposición silenciosa al franquismo, aunque no necesariamente desde posiciones democráticas ${ }^{17}$. ¿Era entonces esa oposición el resultado de unos valores liberal-democráticos? ¿O era más bien por la sensación de frustración generada por la incapacidad de llevar el régimen franquista hacia posiciones más falangistas radicales?

Para defender que Laín era un liberal, algunos autores optaron por contrastar las opiniones de éste con las mantenidas por Calvo Serer quien sin lugar a dudas era un autor integrista y absolutamente convencido que la victoria de 1939 había proclamado la existencia de una única España ante los valedores de esa anti-España que no pertenecían al verdadero sentir nacional. Para el monárquico sólo había una España posible, por lo tanto no había una discusión sobre su ser sino un error ontológico inicial de algunos españoles que optaron por elementos interpretativos no españoles. Era por aquel motivo que tanto la censura como el exilio se habían convertido en las únicas opciones para una gran parte de los españoles no católicos, no monárquicos y no pertenecientes al mundo de la tradición ${ }^{18}$.

Así pues, y ante el exilio, había dos opciones posibles: asimilación o aislación. Laín abría la puerta a aquellos intelectuales que él consideraba asimilables en el nuevo régimen

14 Reinhard BENDIX, Tradition and Modernity Reconsidered, en Comparative Studies in Society and History, vol. 9, núm. 3, abril 1967, p. 292-346.

15 Uno de los primeros y más conocidos estudios sobre la cuestión: Amando DE MiguEL, Sociología del franquismo, Barcelona, Ed. Euros, 1975.

16 Para comprender la configuración y evolución politica del grupo: A. FERRARY, El Franquismo: minorias políticas y conflictos ideológicos 1936-1956, Pamplona: EUNSA, 1993.

17 Para comprender la evolución de Lain Entralgo y sus compañeros de viaje hacia la oposición: Francisco Morente, Dionisio Ridruejo. Del fascismo al antifranquismo, Madrid, Ed. Síntesis, 2006.

18 En varios puntos de su obra el valenciano considera la utilidad del control político, pero en su manifiesto más politico es donde lo desarrolla sin rubor: Rafael CALvo SERER, Teoría de la Restauración, Madrid, Rialp, 1952. 
político, pero no a aquellos que eran anti-Españoles por las ideas que sostenían. Con esa perspectiva en mente, no podemos considerar a Laín como un pensador liberal sino como un académico que no renunciaba a sus fuentes anteriores a la guerra. Porque de eso se trataba, esto es, para Laín algunos autores de la generación del 98 eran perfectamente asimilables en la España de Franco aunque la Iglesia, por ejemplo, considerara a esos hombres como amenazas del orden católico universal ${ }^{19}$. De este modo, autores nacionalistas castellanos como Miguel de Unamuno (1864-1936), la interpretación tolerante lainiana de Marcelino Menéndez Pelayo (1856-1912), o algunos principios autoritarios y modernizadores defendidos por el político aragonés Joaquín Costa (1864-1911) podían ser acogidos como inspiradores de la España de Franco. Del mismo modo, cuando el filósofo madrileño José Ortega y Gasset (1883-1955) volvió a España de su exilio en Portugal, Laín fue uno de los autores que más efusivamente le recibieron. Y, cuando Laín tuvo posiciones académicas de decisión, no dudó en intentar gestionar la vuelta de algunos hombres que vivían en el exilio. Por todo esto podemos considerar que Laín vio en la censura y el exilio armas útiles del régimen pero que se habían utilizado contra algunos autores de manera injusta. De hecho, él mismo les defendió como pensadores abiertos a la discusión, claros y capaces de describir el mundo sin recurrir a oscurantismos, en 1949:

Ortega y Gasset, d’Ors, Marañón, Pérez de Ayala, Ángel Herrera, Américo Castro, Madariaga, Rey Pastor, Azaña [sic]; todos, por diversos que sean en pensamiento y biografia, son hombres de mente clara, almas que prefieren el concepto limpio a la oscura intuición. Por lo que a Ortega atañe -al más joven Ortega-, basta leer la antiunamunesca espístola que a los veintiún años envió a Miguel de Unamuno: «le he de confesar - escribe- que ese misticismo español-clásico, que en su ideario aparece de cuando en cuando, no me convence; me parece una cosa como musgo, que tapiza poco a poco las almas un poco solitarias como la de usted $\rangle^{20} \ldots$

Ante esa voluntad de asimilación, Calvo Serer veía en la mayoría de los autores liberales a hombres que habían renunciado a su hispanidad por haber abrazado los principios de la modernidad occidental. Al entender del monárquico, cualquier acercamiento, por pequeño que aquel fuera, a las ideas modernas llevaba necesariamente a la lucha y el conflicto como bien demostraba la conflagración nacional en la que habían vivido las últimas generaciones de españoles. Además, esos principios rectores que habían defendido los pensadores modernos se habían demostrado inútiles y peligrosos ya que Europa se había enzarzado en un conflicto internacional, 1939-1945, que había condenado a los antiguos EstadoNaciones del viejo continente a la dolorosa decisión de optar o bien por el capitalismo deshumanizador americano o por el comunismo soviético. De este modo, la modernidad estaba sucumbiendo a sus propios valores deshumanizadores y anticristianos.

Por este motivo, tanto los autores de la generación del '98 como la obra de Ortega y Gasset no eran más que obras liberalizantes de algunos de los máximos exponentes de ese mundo moderno y desorientado que llevó a España a la guerra. Para Calvo no eran aquellos autores que defendían la nacionalización de las masas y su integración en un movimiento político unitario los que debían dirigir la vida española, sino aquellos hombres que desde un buen principio se opusieron a todos y cada uno de los elementos de la modernidad occidental. Así pues, Calvo Serer veía en la obra del reaccionario extremeño, Juan Donoso Cortés (18091853), un claro referente de su posición ideológica, incluso su interpretación integrista del

19 Para una introducción al religioso Pildain: G. DE Armas, Pildain: obispo de Canarias, Las Palmas de Gran Canaria, Museo Canario, 1976.

20 Pedro Laín Entralgo, España..., p. 89-90. 
polígrafo santanderino, Marcelino Menéndez Pelayo, sería una clara manifestación de lo que él consideraba la correcta posición de lo que debía ser España ${ }^{21}$. Pero si algún autor era importante en la formación intelectual del monárquico fue el noventayochista reciclado a monárquico integrista, Ramiro de Maeztu y Whitney (1875-1936).

A nuestro entender lo que diferenciaba a ambos autores, o a los grupos que representaban, era su comprensión del mundo moderno y sus implicaciones tanto filosóficas como prácticas. A partir de esas dos cosmovisiones divergentes se derivaron una serie de principios rectores de la sociedad que necesariamente crearon dos culturas políticas contrapuestas. La modernidad dividía también las Españas bajo el franquismo, con lo que el debate podía seguir abierto aunque vigilado por el general Franco.

Con el exilio en silencio y una España derrotada, Laín consideró que no todo lo que había expresado la otra España era erróneo o dañino, de hecho, algunos autores debían ser recuperados para la grandeza nacional. ¿Quiénes eran esos hombres? Pues todos aquellos que compartían con Laín una misma visión de España. Esto condenaba al exilio a aquellos autores que veían en el comunismo, el socialismo o la democracia como elementos hispanos, pero no aquellos que aceptaban parte de la modernidad como pensamiento perfectamente asimilable. En realidad lo que Laín estaba haciendo era una revisión crítica del concepto de modernidad desde posiciones netamente fascistas combinando dos de sus principios rectores: el partido único y la idea de Nación. Y para poder aplicar esa visión política Laín necesitaba superar a modo de Aufhebung hegeliano la tensión interna entre algunos autores que quizá no en la forma pero sí en el fondo compartían algunos principios axiológicos.

Así pues, no nos resultará difícil comprender que en ningún momento Laín rechaza los principios de la modernidad y de la modernización, de hecho los quiere a ambos para España, pero no como la hubieran entendido aquellos autores ilustrados que creían en el individuo y la razón. El falangismo de Laín le lleva a abrazar a los autores de la fin de siècle, aquellos hombres que recelaron de los principios modernos de la Ilustración superándola y aplicando criterios organicistas e irracionales a la vez. Tanto si era el filósofo vitalista alemán Friedrich Nietzsche (1844-1900), o los autores de la sospecha que consideraban al hombre como parte de una comunidad superior conocida como nación o organismo, Laín se veían como un autor post-ilustrado capaz de asimilar parte de esa tradición sin despreciarla, pero ofreciendo algo más moderno que la modernidad misma.

Siendo esa la posición de Laín Entralgo, sus propuestas políticas se derivaban de ese punto inicial. Por eso la solución a los problemas de España no vendría por la oposición sistemática a la modernidad occidental sino que se debía copiar aquello que le fuera útil al país para desechar el resto. A su entender, el Estado español debía estar por encima de cualquier otra consideración, incluida la Iglesia católica. Esta posición estadólatra le granjeó bastantes enemigos entre las filas del mundo católico. Pero es que Laín era un nacionalista convencido y pensaba que sólo mediante la construcción de un Estado moderno y eficiente se podría llegar a competir con otras naciones que ya habían recorrido ese camino. Así, se debía aceptar el principio nacional:

La Revolución Francesa, en lo que a su sentido histórico toca, significa en buena parte la penetración de lo nacional en el mundo de la historia. A partir de entonces, lo nacional no va a ser un mero término étnico o administrativo, sino un permanente motivo político o histórico: «honon» nacional, espíritu «nacional», política «nacional», etc. ${ }^{22}$.

21 Rafael Calvo Serer, La significación cultural de Menéndez Pelayo y la «Historia de su fama", Separata de la Revista Arbor, Madrid, 1951.

22 Pedro Lain Entralgo, Los valores... p. 22. 
El nacionalismo lainiano consideraba que la lengua castellana había fundamentado la unidad de España y que por lo tanto los españoles debían dejar a un lado sus identidades locales para superar esas tensiones y unirse a la nueva España que ofrecía un futuro sin las querellas que habían afectado al país hasta 1939. Así pues, el Estado central debía ser todopoderoso y la nación española debía fundamentarse en aquello que todos los españoles compartían: la lengua castellana y su tradición. Este punto sería una zona de conflicto con las posiciones calvosererianas como se verá más abajo.

De este modo, el Estado-Nación en Laín Entralgo pasaba a ser el centro de la vida pública, sólo accesible al mismo mediante la adhesión a un partido único: Falange Española Tradicionalista. Tanto durante la guerra como después de ella Laín y el grupo de falangistas que frecuentaba optaron abiertamente por la idea de promover la politización de los españoles mediante un partido todopoderoso que debería ser el que organizase las instituciones políticas españolas. Como se ha remarcado más arriba, no le interesaba en absoluto el rol público de la Iglesia, aunque lo tendría, siempre que la institución vaticana comprendiera que la raison d'État era el futuro, no la pretensión de unificar Trono y Altar. Así pues, el partido único debía integrar a todos los españoles y superar las políticas liberales típicas que dividían a la nación entre izquierdas y derechas dando como resultado una política plenamente nacional con tintes aparentemente socialistas en ocasiones y siempre profundamente nacionales:
Decir que estos dos imperativos históricos, la moral nacional y la moral del trabajo, andaban cada vez más divorciados desde 1848, es casi descubrir el Mediterráneo. Las masas proletarias fueron desviándose de toda idea nacional y de toda religiosidad, entendida ésta en su recto y habitual sentido. Las gentes vulgares suelen hablar de predicaciones nefastas, corruptoras del buen obrero, y de otras burdas candideces por el estilo. En rigor, el proletario de 1890 a 1930 apenas tenía posibilidad histórica -dejo a salvo el heró́smo o un especial auxilio de la gracia- para ser patriota o religioso ${ }^{23}$.

Y esto nos lleva al último punto defendido por Laín: la necesidad de dejar atrás la forma monárquica de gobierno para abrazar la mucho más moderna y eficiente república en la que no se ocuparía la Jefatura del Estado en razón de nacimiento sino de capacidades para el gobierno de la Nación. De este modo, Francisco Franco habría demostrado suficientemente su capacidad de organización y gestión durante los años de la guerra convirtiéndose en un dirigente tan o más apto que cualquier Borbón o Austria. En palabras del mismo Laín:

Esta misma convicción puede penetrar, y de hecho ha penetrado en la conciencia de muchas personas reales: si hemos podido ver a un Kronprinz de Habsburgo al servicio, no sólo de la Alemania actual, sino de su mismo Régimen «monárquico» - ¿qué Monarquía más perfecta, en cuanto Monarquía, que la de Adolfo Hitler?-, no creo que en tal hecho haya causa diferente de la expuesta, miradas las cosas en su centro ${ }^{24}$.

Ante esa visión modernizadora de España, Calvo Serer se alzó como opción anti-moderna. Para aquel, cualquier intención de domesticar la modernización era un ejercicio fútil que sólo llevaría a sus autores a un fracaso ineludible. La modernidad había desplegado una ideología política fundamentada en la raison d'État y el poder absoluto del Estado alejando la ética cristiana de la política y buscando en último término el poder absoluto del soberano sobre otras instituciones o corporaciones. Para Calvo el Estado moderno que defiende Laín es tan erróneo como lo podían ser los Estados Unidos de Norteamérica o la Unión Soviética

23 Pedro Lain Entralgo, Los valores..., p. 33.

24 Ibid., p. 59. 
puesto que todos ellos eran manifestaciones de la misma modernidad que había llevado a Europa al colapso civilizatorio.

A diferencia de Laín, Calvo Serer proponía un Estado corporativo al estilo de lo ofrecido por algunos autores carlistas o reaccionarios. El Estado tendría muchísimo poder, claro está, pero no por ello éste negaría la importancia de la Iglesia y otras instituciones que deberían jugar un papel fundamental en la gestión de la vida pública española. Así pues, se avanzaría hacia un modelo político corporativo que evitara los problemas de la falta de ética en la toma de decisiones. De manera absolutamente contraria a lo que decía Laín, Calvo consideraba que la solución de los problemas de España no vendría jamás de un Mussolini sino de una opción totalmente hispana fundamentada en lo que España hizo cuando se convirtió en imperio, esto es, seguir el camino de la fe. De este modo, la política debe servir, en parte, a la fe y a la historia:

$[\ldots]$ el pensamiento contrarrevolucionario no pretende parar la Historia, ni es una vuelta nostálgica al pasado. Por el contrario, domina en aquél la idea de que la Historia es irrepetible. Lo que sí hace es tener presente que en el fluir histórico hay valores eternos que son precisamente los que deben configurar el pensamiento y la sociedad. Por negar esto es por lo que el pensamiento revolucionario acaba deshaciéndose en el relativismo y el historicismo ${ }^{25}$.

Por lo tanto un Estado corporativo hispano con una nación unificada sin fisuras, pero no mediante la lengua y la cultura, sino la religión católica que todos los españoles comparten. Tal y como lo comprendía Calvo Serer, el castellano es la lengua común a todos los españoles, pero no porque algunos españoles recen o hablen en catalán, en valenciano, en vasco o en gallego eso les convertía en malos ciudadanos. Así pues, lo que unía a todos y cada uno de los españoles era la fe y su misión, no la lengua que podía generar divisiones innecesarias. Para Calvo lo importante era el proceso de Reconquista y el sentido de imperio cristiano que tuvieron muchas generaciones de castellanos, aragoneses, vascos, navarros o gallegos.

Pero quizá la mayor pregunta era ¿cómo se acedía al sistema político ofrecido por este católico integrista? Este nunca participó o se unió al partido único creado por Franco fusionando a Tradicionalistas y Falangistas. Lo que ofreció fue totalmente distinto a lo que había sugerido el falangista, para el monárquico era necesario un Estado corporativo en el que familias, empresas, religiosos y otras instituciones con cierta importancia fueran todas representadas de alguna manera. De este modo, Calvo rechazaba también una de las contribuciones fundamentales de la modernidad: los partidos políticos.

Y, por último, Calvo Serer también se opone a la propuesta lainiana de una república moderna dirigida por un dictador todopoderoso apoyándose en un partido de masas. Según el monárquico sólo un rey podía gobernar dignamente el futuro de España, cosa que no implicaba el fin de Franco, ya que ese sería su perfecto Presidente o Jefe de Gobierno. Lo más importante es que ese rey mantuviera en alto los valores tradicionales de la España eterna para no caer en los sucesivos errores antirrevolucionarios. Según Calvo:

[...] ]algunos intentos anticomunistas tienen sus raíces en el mismo espíritu revolucionario. El influjo de Nietzsche es innegable en Hitler y en Mussolini. El catolicismo liberal, que se inicia débilmente en la época de la Restauración, primera mitad del siglo XIX, en nuestros dias la fuerza con la que los demócratas-cristianos intentan combatir el espíritu

25 Rafael Calvo Serer, España..., pág.25. En este fragmento consideramos que Calvo Serer se defiende de los ataques que los falangistas cercanos a Laín le están profiriendo por considerar que no se puede detener el tiempo. 
de la Revolución; pero en ellos, en sus bases ideológicas, se evidencia la influencia de su mismo enemigo ${ }^{26}$.

Así pues, si el poder totalitario de los fascismos europeos se fundamenta en aquello mismo que quieren evitar no harán más que mantener las condiciones que llevaron a Europa a la necesidad de establecer estos regímenes. Sólo hay una solución a las cuestiones planteadas por la modernidad y no es más que su negación absoluta.

Para Calvo todo sistema político que pretenda superar la tensión introducida por la modernidad en España debe volver a los virtuosos gobiernos de aquellos dirigentes que Ilevaron a España al Imperio ante aquellos países que abrazaron los principios modernos, así:

en España, desde 1931, a la caída misma de la Monarquía, víctima de los principios, que no de los resultados, del sufragio universal, esta doctrina fué [sic] defendida por Acción Española. Por ella, España ha podido liberarse de la corriente en que está sumergida Europa entera. Por esto, España pasó el proceso de la Guerra preventiva ${ }^{27}$.

Este fragmento es una defensa profunda de los principios que vehicularon la obra de Ramiro de Maeztu y las ideas que articularon Acción Española en tiempos de la Segunda República:

No hay en la Historia universal obra comparable a la realizada por España, porque hemos incorporado a la civilización cristiana a todas las razas que estuvieron bajo nuestra influencia. Verdad que en estos dos siglos de enajenación hemos olvidado la significación de nuestra Historia y el valor de lo que en ella hemos realizado, para creernos una raza inferior y secundaria. En el siglo XVII, en cambio, nos dábamos plena cuenta de la trascendencia de nuestra obra; no había entonces español educado que no tuviera conciencia de ser España la nueva Roma y el Israel cristiano ${ }^{28}$.

De este modo, Calvo Serer no ve en la república conservadora o fascista un sistema político que pueda funcionar. De hecho, las repúblicas no funcionan ni en España ni en ninguna parte puesto que la Alemania nazi lo era, la Unión Soviética también y los Estados Unidos también, y todos estos países, a entender de Calvo Serer, están en situación de decadencia y crisis espiritual, hecho que en último término es lo que interesa al autor valenciano. Estos regímenes han mostrado ser modernos en cuanto a técnica y política, pero no les ha servido de nada cuando han ido a la guerra, de hecho, sólo ha hecho los resultados peores. En sus múltiples viajes por Europa constata continuamente que la situación en la que se encuentra el continente es insostenible y si se quiere salir de esa crisis atroz se debe volver a la fe y a la tradición.

Por lo tanto, ambos autores pusieron de relieve la tensión existente entre los miembros de la coalición anti-republicana liberal. Todos ellos estaban de acuerdo en destruir la herencia republicana, pero no podían acceder a un acuerdo en relación a la salida de la guerra, esto es, sus proyectos políticos en positivo divergían radicalmente. Evidentemente, todos estaban de acuerdo en que la democracia no podía llevar a ninguna parte, lo que debía hacerse era mantener el orden de una dictadura aunque no pudieran ponerse de acuerdo en qué tipo de régimen autoritario o totalitario.

Mientras que para Laín Entralgo el Estado era la pieza fundamental de la «nueva España), para Calvo Serer debía ser un Estado regido en concordancia con los principios

26 Ibid., p. 20

27 Ibid., p. 60-1.

28 Ramiro de Maeztu, Defensa de la Hispanidad, Madrid, Cultura Española, 1941, p. 118. 
cristianos mantenidos por la Iglesia Católica Romana. ¿Significa eso que Laín era un autor secular? De ninguna manera, para el falangista la religión formaba parte integral de la identidad de los españoles y sólo mediante el respeto a los principios católicos España se había convertido en lo que era. De este modo, Laín acentuaba principios nacionalistas más políticos como el partido, la lengua nacional, la ideología mantenida por el fascismo europeo y la voluntad de unir a todos los españoles bajo un mismo movimiento. Por eso consideramos que Laín defiende un sistema político totalitario nacional y católico ya que antepone elementos políticos sin negar los religiosos, y totalitario porque considera que la planificación nacional debe recaer totalmente en manos del Estado.

Por su parte, Calvo Serer estaba convencido de la necesidad de volver a un sistema político tocado por el hecho religioso. Con ello no negaba la función de la política o del régimen moderno en el que el partido y el Estado jugaran un papel hegemónico, sencillamente pensaba que no se podía negar el hecho religioso en el mundo político. $\mathrm{Si}$ ello sucedía, los políticos caerían en el exceso y la radical e inevitable revolución que llevaba al mundo moderno y sus problemas. De este modo, podríamos decir que Calvo fue un autoritario católico y nacional, o católico-nacional, puesto que antepuso los principios de la fe y del sentido de misión cristiano al del mundo de la política post-westfaliana. Y si le consideramos autoritario no es porque prefiera un sistema político más cercano a la democracia que el que defendía Laín, en realidad, consideraba que el Estado de raíz hegeliana no podría construir un mundo justo y recto como afirmaban sus defensores.

Pero estas discusiones sobre la forma política a usar una vez derrotada la república quedaron sepultadas por los movimientos políticos del general Franco. A finales de la década de los cuarenta el régimen parecía aislado y sin capacidad de evolucionar hacia una situación más satisfactoria dada la coyuntura internacional. La derrota de las fuerzas del Eje en 1945, la creación de las Naciones Unidas y el inicio de la Guerra Fría hizo que España se convirtiera por su pasado reciente en un país aislado y sin aliados. Por eso varios intelectuales de la coalición empezaron a ofrecer soluciones alternativas a la conseguida en 1939 con la victoria del generalísimo sobre las fuerzas republicanas. De este modo, no es difícil de comprender que detrás de esa querella intelectual había un proyecto político de futuro para convencer a las naciones victoriosas de la Segunda Guerra Mundial de los cambios operados en la «nueva España».

Si Laín había visto cómo su fascismo partitocrático y estadólatra había sido derrotado en 1945 debido a la toma de Berlín por parte del Ejército Rojo de Stalin, no pasaba lo mismo con su intención de asimilar lo posible de la España del exilio para dar señales de cambio a los Estados Unidos y a los países europeos. Por su parte, Calvo nunca vio su proyecto político ser derrotado; de hecho, el monarca, Juan de Borbón (1913-1993), estaba esperando en Portugal; los partidarios de una España tradicionalistas estaban preparados para aceptar parte de la responsabilidad de gobierno; y, por último, la Iglesia ya estaba colaborando en el control social de los españoles que deseaban los integristas.

El problema con el que toparon esas dos visiones del futuro español fue la doble maniobra de Franco. En un primer momento el generalísimo supo usar la nueva situación internacional creada a partir de la división del mundo en dos bloques para ganarse el favor de los Estados Unidos y el Vaticano en 1953, cerrando provisionalmente la presión internacional; $\mathrm{y}$, en segundo lugar, la operación de cambio en el partido único y las nuevas ideas tecnocráticas que debían sacar a España de la crisis en la que se encontraba a finales de la década de los cincuenta. Mientras Franco construía su nuevo futuro, Calvo y Laín cayeron de sus posiciones de poder y fueron condenados a una oposición más o menos 
cómoda poniendo de relieve que Franco empezaba a confiar en una nueva generación de franquistas no formados en los grupos de preguerra y sus ideologías superadoras del poder del Caudillo. Los tecnócratas perpetuaron el poder de Franco, tanto como superaron las respuestas políticas de aquellos que habían ayudado al Generalísimo a hacerse con el poder. 